Original article

\title{
Role of costimulatory molecules in immune response of patients with cutaneous leishmaniasis
}

\author{
Cecilia Favali ${ }^{\text {a }}$, Dirceu Costa ${ }^{\text {a }}$, Lilian Afonso ${ }^{a}$, Viviane Conceição ${ }^{\text {a }}$, Andréa Rosato ${ }^{\text {a }}$ \\ Fabiano Oliveira ${ }^{\text {a }}$, Jackson Costa ${ }^{\mathrm{a}}$, Aldina Barral ${ }^{\mathrm{a}, \mathrm{b}, \mathrm{c}}$, Manoel Barral-Netto ${ }^{\mathrm{a}, \mathrm{b}, \mathrm{c}}$, Claudia \\ Ida Brodskyn ${ }^{\mathrm{a}, \mathrm{c}, \mathrm{d}, *}$ \\ ${ }^{a}$ Laboratório de Imunoparasitologia, Centro de Pesquisas Gonçalo Moniz, Fundação Oswaldo Cruz (FIOCRUZ), Rua Waldemar Falcão, 121, Salvador, \\ Bahia 40295-001, Brazil \\ ${ }^{\mathrm{b}}$ Faculdade de Medicina, Universidade Federal da Bahia (UFBA), Salvador, Bahia, Brazil \\ ${ }^{\mathrm{c}}$ Institute of Investigation in Immunology (iii)/Millenium Institute, Salvador, Bahia, Brazil \\ ¿ Instituto de Ciências da Saúde da Universidade Federal da Bahia, Salvador, Bahia, Brazil
}

Received 29 March 2004; accepted 22 September 2004

Available online 13 December 2004

\begin{abstract}
T cell-mediated immunity is critical in resistance against Leishmania parasites, and T cell activation requires signals provided by costimulatory molecules. Herein we evaluated the role of costimulatory molecules on cytokine production and T cell surface molecule expression by peripheral blood mononuclear cells (PBMC) from cutaneous leishmaniasis (CL) patients. PBMC from CL patients were stimulated with soluble Leishmania antigen (SLA, $10 \mu \mathrm{g} / \mathrm{ml}$ ), in the presence or absence of soluble CTLA4-Ig to block CD28-B7 interaction or in the presence or absence of anti-human CD40L to block CD40-CD40L interaction. Supernatants were harvested to evaluate tumor necrosis factor alpha (TNF- $\alpha$ ), interleukin 10 (IL-10), transforming growth factor beta (TGF- $\beta$ ) and interferon gamma (IFN- $\gamma$ ) production by ELISA. Cells were harvested after $48 \mathrm{~h}$ of culture, stained for specific activation markers and analyzed by flow cytometry. Results show that the blockade of CD28-B7 interaction by CTLA4-Ig downmodulated IFN- $\gamma$, IL-10, and TNF- $\alpha$ secretion by PBMC from CL patients. No alteration was detected on either TGF- $\beta$ production or the expression of CTLA44 or CD 25 on CD4 ${ }^{+}$and CD8 ${ }^{+}$T cells. When the CD40-CD40L interaction was blockade using anti-CD40L, we did not observe changes in cytokine production or in surface molecule expression. The blockade of the CD28-B7 interactions by CTLA4-Ig also did not alter cytokine production in volunteers immunized against tetanus toxoid (TT). Taken together, these data suggest that the interaction of CTLA4 and CD28-B7 is a TGF- $\beta$-independent mechanism that specifically downmodulates the immune response in cutaneous leishmaniasis patients.
\end{abstract}

(c) 2004 Published by Elsevier SAS.

Keywords: Cutaneous leishmaniasis; Cytokines; Immunomodulation

\section{Introduction}

The cell-mediated immune response is fundamental in infection and disease progression in leishmaniasis. Th1-type cytokines are involved in resistance, whereas Th2-type

Abbreviations: CL, cutaneous leishmaniasis; IFN- $\gamma$, interferon gamma; IL-10, interleukin 10; LF, limit of flocculation; PBMC, peripheral blood mononuclear cells; SLA, soluble Leishmania antigen; TGF- $\beta$, transforming growth factor beta; TNF- $\alpha$, tumor necrosis factor alpha; TT, tetanus toxoid.

* Corresponding author. Tel.: +55-71-356-4320.

E-mail address: brodskyn@ @pqgm.fiocruz.br (C.I. Brodskyn). responses are linked to susceptibility to Leishmania infection [1]. Cytokine balance is also implicated in the clinical spectrum of human leishmaniasis [2].

Besides the signal delivered by the peptide antigen after engaging the TCR, effective T cell activation requires a second signal provided by surface molecules on the antigenpresenting cell (APC), which are collectively known as costimulatory molecules $[3,4]$. The CD28-B7 receptorligand system upregulates cytokine gene expression and promotes T cell expansion and differentiation [5], and is important in mouse resistance against Leishmania major [6]. The CD40-CD40L interaction is also important in T cell activa- 
tion, due to the increased IL-12 production by APC, which directs Th1 response development and has been implicated in elimination of intracellular pathogens [7]. Mice deficient in CD40 or in CD40L do not produce IL-12 and interferon gamma $(\mathrm{IFN}-\gamma)$ and exhibit more severe disease upon $L$. major infection [8]. By means of an in vitro priming assay of human peripheral blood mononuclear cells (PBMC) and Leishmania, it has been shown that the CD86 (B7-2)CD28 interaction has an essential role in the initial activation of the human anti-Leishmania immune cell response, as its blockade downregulated IL-12 and IFN- $\gamma$ production [9]. However, little is known about the importance of such interactions in maintaining an ongoing immune response in cutaneous leishmaniasis (CL) patients. Our strategy consisted of blocking CD28-B7 or CD40-CD40L interactions during Leishmania antigen stimulation of PBMC from CL patients, and evaluating cytokine production and $\mathrm{T}$ cell surface molecule expression by such cells.

\section{Material and methods}

\subsection{Patients}

CL patients $(n=35)$ were selected at the Centro de Referência Pirajá da Silva, Jequié (Bahia, Brazil), an endemic area for L. braziliensis [10]. All patients presented an active lesion compatible with CL as well as one of the following characteristics: (i) positive intradermal reaction (Montenegro test) to Leishmania antigen; (ii) detection of Leishmania parasites in the biopsy samples after microscopic examination of histological section; or (iii) clinical cure following treatment with Glucantime ${ }^{\circledR}\left(20 \mathrm{mg} \mathrm{Sb}^{5+}\right.$ per kg/day). Blood was collected after informed consent, obtained from either the patient or legal guardian. All procedures were approved by the Ethical Committee of Centro de Pesquisas Gonçalo Moniz, Fundação Oswaldo Cruz, BA, Brazil. Patients, male (21/35; 60\%) or female $(14 / 35 ; 40 \%)$ gender, had a mean age of 27 years and showed mean lesion duration of 55 days $(55 \pm 38.6)$, and the mean lesion diameter was $3.3 \mathrm{~cm}$. Most patients $(21 / 35 ; 60 \%)$ presented detectable regional lymph nodes at the time of diagnosis. Skin test was positive in $88.5 \%$, negative in $2.8 \%$ and not performed in $22.8 \%$ of the patients. Amastigotes were visualized in $38.2 \%$ of biopsy samples.

\subsection{Tetanus toxoid-immunized individuals}

Heparinized venous blood from 10 individuals immunized with tetanus toxoid (TT) was collected to perform assays using CTLA4-Ig. Their last immunization with TT occurred between 6 and 24 months before blood collection. PBMC were stimulated with 5 limit of flocculation (LF)/ml [11], supernatants were harvested, and cytokine production was measured by ELISA.

\subsection{Antigen}

Soluble Leishmania antigen (SLA) was prepared as described elsewhere [12]. Briefly, stationary-phase promas- tigotes were ultrasonicated and centrifuged at 20,000 $\times g$ for $2 \mathrm{~h}$. The supernatant was used at a final concentration of $10 \mu \mathrm{g} / \mathrm{ml}$.

\subsection{Reagents/antibodies}

Human CTLA4-Ig $(0.5 \mathrm{mg} / \mathrm{ml}$ purified CD152, Ancell, Bayport, MN) was used at $5 \mu \mathrm{g} / \mathrm{ml}$ to block the CD28B7 interaction [9]. Neutralizing anti-human CD40L (antihuman CD40L, clone TRAP1; Pharmingen, San Diego, CA) was used at $10 \mu \mathrm{g} / \mathrm{ml}[9,13]$. Purified rat IgG2a monoclonal immunoglobulin isotype clone R35-95 and purified mouse IgG1 monoclonal immunoglobulin isotype clone 107.3 (Pharmingen) were used as irrelevant antibody controls.

\subsection{Cell culture}

PBMC were obtained from heparinized venous blood by passage over a Ficoll Hypaque gradient (Sigma-Aldrich). PBMC were washed three times and resuspended at a concentration of $5 \times 10^{6}$ cells per ml in RPMI-1640 medium (Gibco, NY) supplemented with $2 \mathrm{mM}$ L-glutamine, penicillin $(100 \mathrm{U} / \mathrm{ml})$, streptomycin $(100 \mu \mathrm{g} / \mathrm{ml})(\mathrm{Gibco})$ and $10 \%$ heat-inactivated human AB serum (Sigma-Aldrich).

Cells were plated in 24-well tissue culture plates (Costar, Corning Incorporated, NY) at a concentration of $5 \times 10^{6}$ cells per $\mathrm{ml}$ and incubated at $37{ }^{\circ} \mathrm{C}, 5 \% \mathrm{CO}_{2}$. Stimulation was performed by addition of SLA $(10 \mu \mathrm{g} / \mathrm{ml})$ in the presence or not of CTLA4-Ig $(5 \mu \mathrm{g} / \mathrm{ml})$ (Ancell, MN) or anti-human CD40L (10 $\mu \mathrm{g} / \mathrm{ml})$ (Pharmingen). Supernatants were harvested 24, 48 and $96 \mathrm{~h}$ after in vitro stimulation and maintained at $-20{ }^{\circ} \mathrm{C}$ until use.

\subsection{Cytokine ELISA}

Tumor necrosis factor alpha (TNF- $\alpha$ ), interleukin 10 (IL$10)$, IFN- $\gamma$ (Pharmingen) and transforming growth factor beta (TGF- $\beta$ ) (Promega, Madison, WI) levels were determined using commercially available ELISA kits. The assays were performed according to the manufacturer's instructions.

\subsection{Flow cytometry}

After $48 \mathrm{~h}$ of culture, non-adherent cells were harvested for flow cytometric analyses. Briefly, $5 \times 10^{5}$ cells were incubated with PBS plus $1 \%$ bovine serum albumine and $0.1 \%$ sodium azide and incubated with $20 \%$ fetal calf serum to block FcR. Cells were then double stained with specific antibodies conjugated to fluorochromes FITC anti-human CD4 (clone RPA-T4), FITC anti-human CD8 (clone RPA-T8), PE antihuman CD25 (clone M-A251) and PE anti-human CTLA4 (clone BNI3) or isotype control antibodies (PE or FITClabeled IgG1, $\kappa$ chain clone MOPC-21) (Pharmingen). Cells were analyzed on FACSort (Becton Dickinson, CA) and Cell Quest programs (Becton Dickinson).

\subsection{Statistical analysis}

Statistical analyses were performed on Graphpad-Prism 3.0 (Graphpad Software, CA) using Wilcoxon matched pair 
tests. Correlation was obtained by Pearson's test. Values of $P$ $<0.05$ were considered significant.

\section{Results}

\subsection{CD28-B7 interaction is implicated in cytokine} production by PBMC from cutaneous leishmaniasis patients

The use of CTLA4-Ig to block the CD28-B7 interaction on PBMC culture from CL patients stimulated with SLA led to significant differences in cytokine production. In the presence of CTLA4-Ig, 16 out of 19 (84\%) individuals tested showed a reduction in TNF- $\alpha$ production (median values diminished from 271.8 to $37 \mathrm{pg} / \mathrm{ml}(P=0.0003))$. Two individuals had undetectable cytokine levels even in the absence of CTLA4-Ig (Fig. 1A). IL-10 was also downmodulated in nine patients tested (from 75.24 to $9.11 \mathrm{pg} / \mathrm{ml}(P=0.0039)$ ), whereas the remaining nine patients tested had undetectable levels of IL-10 even in the absence of CTLA4-Ig and, for this reason were excluded from analyses (Fig. 1B). The use of CTLA4-Ig also led to a downmodulation in IFN- $\gamma$ in 17 out of $19(89 \%)$ patients tested (median values from $1966 \mathrm{pg} / \mathrm{ml}$ when cells were stimulated with SLA and in the presence of CTLA4-Ig to $1262 \mathrm{pg} / \mathrm{ml}(P=0.001)$ (Fig. 1C). The use of isotype antibodies did not show any differences in cytokine production, (data not shown).

Therefore, the use of CTLA4-Ig showed a reduction in IL-10, IFN- $\gamma$ and TNF- $\alpha$ production by PBMC from CL patients. We performed different correlation analyses using the results described above, in order to understand the immunomodulation induced by CD28-B7 blockade. We found a positive correlation only between IFN- $\gamma$ and TNF- $\alpha(P$ $=0.0394$ ) reductions when CTLA4-Ig was used to block CD28-B7 interactions (Fig. 2).

Considering that TGF- $\beta$ is an important immunomodulatory cytokine in leishmaniasis, we investigated its production in PBMC stimulated with SLA in the presence or not of CTLA4-Ig. TGF- $\beta$ production was not significantly altered by blocking CD28-B7 interaction-a median of $40.4 \mathrm{pg} / \mathrm{ml}$ in the absence of CTLA4-Ig and of $42.5 \mathrm{pg} / \mathrm{ml}$ in the presence of CTLA4-Ig $(P=0.7089)$ (Fig. 3).

\subsection{CD28-B7 interaction is not involved in unrelated stimulus}

To verify whether the effects of CD28-B7 blockade constitute a specific phenomenon observed in CL patients, we used PBMC from individuals immunized with TT $(5 \mathrm{LF} / \mathrm{ml})$ in the presence or absence of CTLA4-Ig $(5 \mu \mathrm{g} / \mathrm{ml})$. Concerning TNF- $\alpha$ production, TT stimulation led to a production of $642 \mathrm{pg} / \mathrm{ml}$ of TNF- $\alpha$, whereas in the presence of CTLA4-Ig, we did not significantly alter this finding $(493.5 \mathrm{pg} / \mathrm{ml}(P$ $=0.5787))$. IL-10 (31.54 versus $21.32 \mathrm{pg} / \mathrm{ml}(P=0.6248))$ and IFN- $\gamma(537$ versus $404.5 \mathrm{pg} / \mathrm{ml}(P=0.2475))$ production
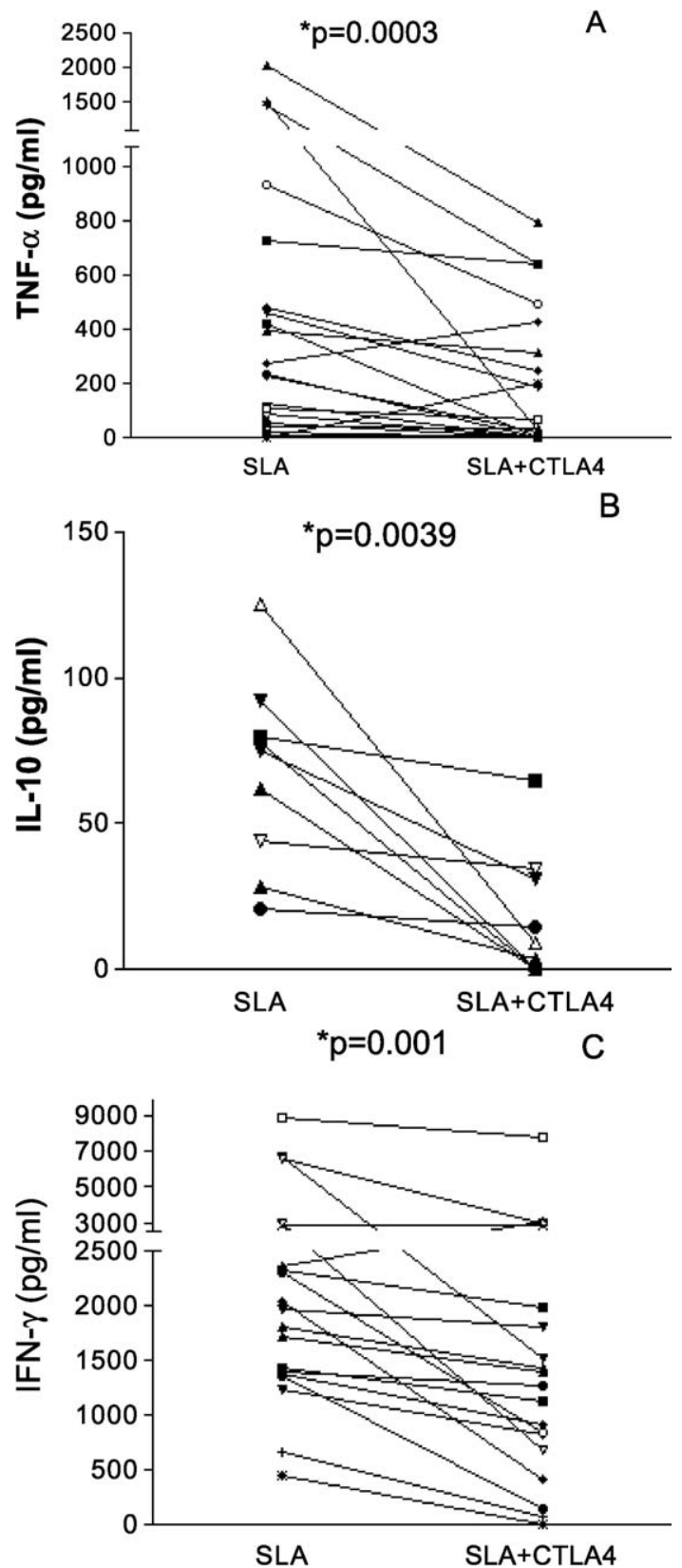

Fig. 1. TNF- $\alpha$ (a), IL-10 (b) and IFN- $\gamma$ (c) production in culture supernatants from PBMC of CL patients stimulated with SLA $(10 \mu \mathrm{g} / \mathrm{ml})$ in the presence or absence of soluble CTLA4- $\operatorname{Ig}(5 \mu \mathrm{g} / \mathrm{ml})$. Results are expressed in $\mathrm{pg} / \mathrm{ml}$. Each point represents data from one individual. The Wilcoxon matched pairs test was performed and considered significant with $P<0.05$.

were practically unaltered in the absence or presence of CTLA4-Ig (Fig. 4) respectively. These data show that the CD28-B7 interaction seems to be important in leishmaniasis and is not required in other models.

\subsection{Blocking CD28-B7 interaction does not alter expression of $T$ cell surface markers}

The fact that CTLA4-Ig downmodulated IFN- $\gamma$, IL-10 and TNF- $\alpha$ production led us to investigate whether $\mathrm{T}$ cells obtained from SLA-stimulated cultures, in the presence or not of CTLA4-Ig, showed any alterations in the expression 


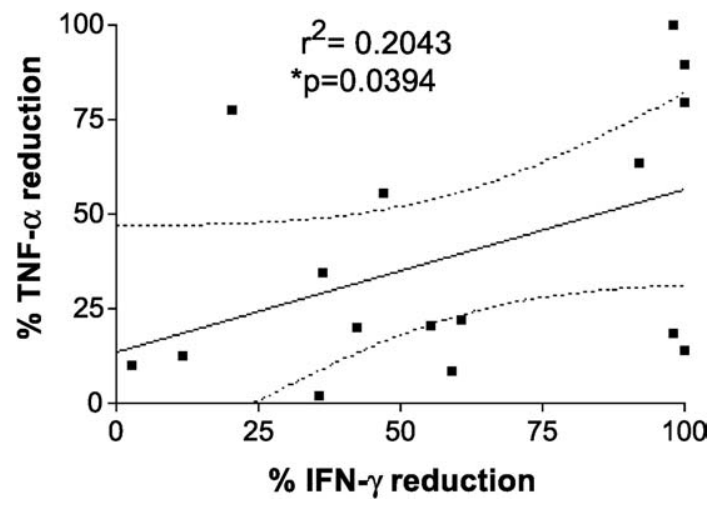

Fig. 2. Reductions in TNF- $\alpha$ and IFN- $\gamma$ production were calculated considering PBMC stimulated with SLA only $(10 \mu \mathrm{g} / \mathrm{ml})$; total production and the reduction observed in the presence of CTLA4-Ig $(5 \mu \mathrm{g} / \mathrm{ml})$. Percentage of reductions was plotted, and a positive Pearson's is shown.

of surface markers. We did not observe any statistically significant changes in CD25 or CTLA4 $(P>0.05)$ expression on either $\mathrm{CD}^{+}$or $\mathrm{CD}^{+} \mathrm{T}$ cells, when we compared cells stimulated with SLA in the presence or absence of CTLA4Ig. (Fig. 5).

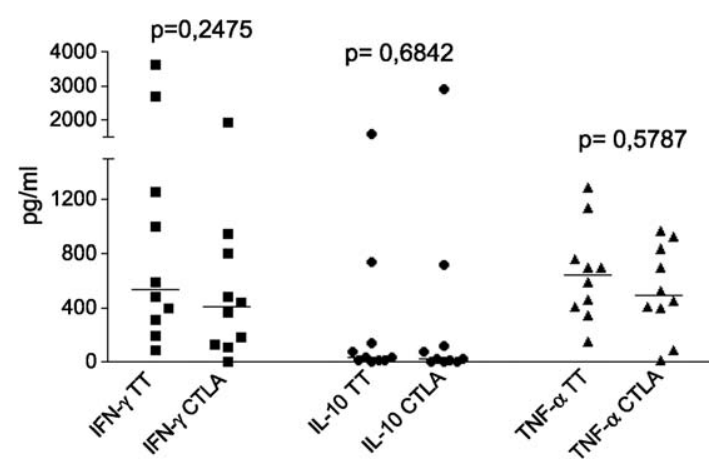

Fig. 3. TGF- $\beta$ production in culture supernatants from PBMC of CL patients stimulated with SLA $(10 \mu \mathrm{g} / \mathrm{ml})$ in the presence or absence of soluble CTLA4- $\operatorname{Ig}(5 \mu \mathrm{g} / \mathrm{ml})$. Results are expressed in $\mathrm{pg} / \mathrm{ml}$. Each point represents data on one individual.

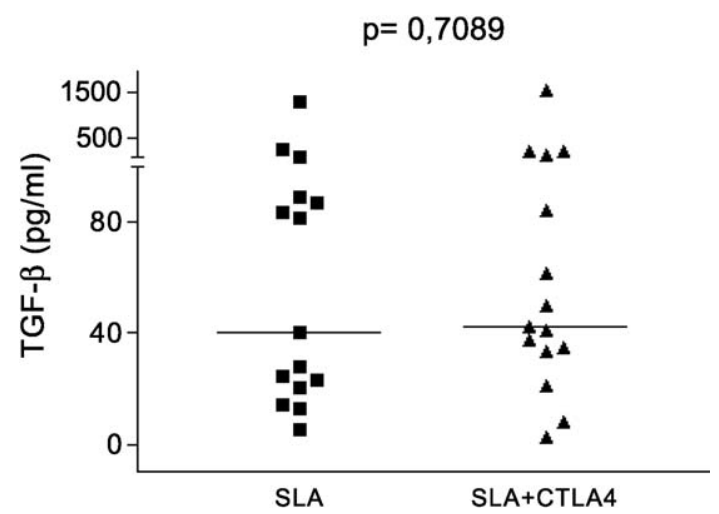

Fig. 4. TNF- $\alpha$ (squares), IL-10 (circles) and IFN- $\gamma$ (triangles) production in culture supernatants from PBMC of TT-immunized individuals stimulated with TT $(5 \mathrm{LF} / \mathrm{ml})$ in the presence or absence of soluble CTLA4- $\operatorname{Ig}(5 \mu \mathrm{g} / \mathrm{ml})$. Results are expressed in $\mathrm{pg} / \mathrm{ml}$. Each point represents data on one individual.

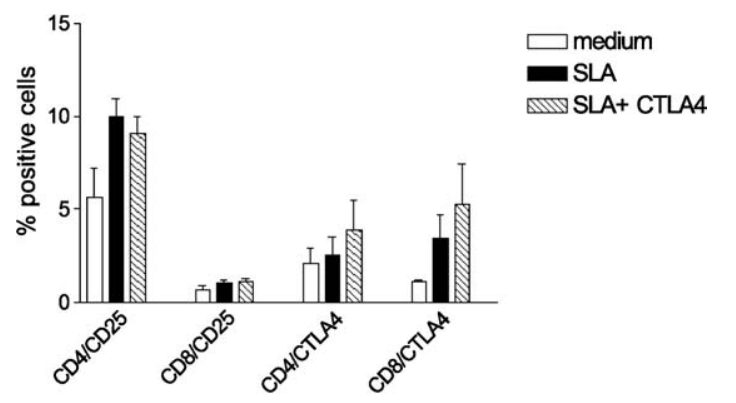

Fig. 5. CD28-B7 does not alter expression of T cell surface markers. Flow cytometric phenotypic characterization of non-adherent cells from CL patients after $48 \mathrm{~h}$ culture. The data shown are median values from six different donors analyzed by the Wilcoxon matched pairs test, comparing SLA $(10 \mu \mathrm{g} / \mathrm{ml})$ stimulation only and in the presence of soluble CTLA4-Ig $(5 \mu \mathrm{g} / \mathrm{ml})$.

\subsection{Blockade of CD40-CD40L interaction does not alter cytokine production by PBMC from cutaneous leishmaniasis patients}

CD40-CD40L blockade did not modulate TNF- $\alpha$ production. Median values were $239.3 \mathrm{pg} / \mathrm{ml}$ when cells were stimulated with SLA only and $120.6 \mathrm{pg} / \mathrm{ml}(P=0.3344)$ in the presence of SLA plus anti-CD40L. There was a downmodulation in 11 out of 24 tested patients, while production was augmented in four of them (Fig. 6A).

IL-10 production was undetectable in 11 out of 22 patients. In patients with detectable IL-10 (11/22), alteration in IL-10 production was not significant, varying from $62.48 \mathrm{pg} / \mathrm{ml}$ in the presence of SLA to $38.06 \mathrm{pg} / \mathrm{ml}$ in the presence of SLA plus anti-CD40L $(P=0.4131)$ (Fig. 6B). No significant alteration was observed in IFN- $\gamma$ production either, when cells were stimulated with SLA or with SLA plus anti-CD40L (1986 versus 1895 pg/ml, respectively) (Fig. 6C).

\section{Discussion}

Infection and disease outcome in leishmaniasis are dependent on both the parasite and the host immune response. Cellmediated immune response against Leishmania is dependent on costimulatory activity, to initiate the antigen-specific $\mathrm{T}$ cell responses as well as to induce microbicidal mechanisms on infected APC. CD28-B7 [6] and CD40-CD40L [14] interactions are associated with resistance to infection in murine models; the importance of costimulation on human responses to Leishmania, however, is not totally elucidated.

We observed an important reduction in TNF- $\alpha$, IL-10 and IFN- $\gamma$ secretion in PBMC from CL patients after CD28B7 blockade. Our data suggest that the CD28-B7 costimulatory pathway is important in the human immune response to Leishmania. Brodskyn et al. [9] showed that the presence of CTLA4-Ig diminished IFN- $\gamma$ production in an in vitro priming assay, where $\mathrm{T}$ cells were stimulated with L. majorinfected autologous macrophages, but it did not alter IL10 production, suggesting that it is an IL-10-independent 

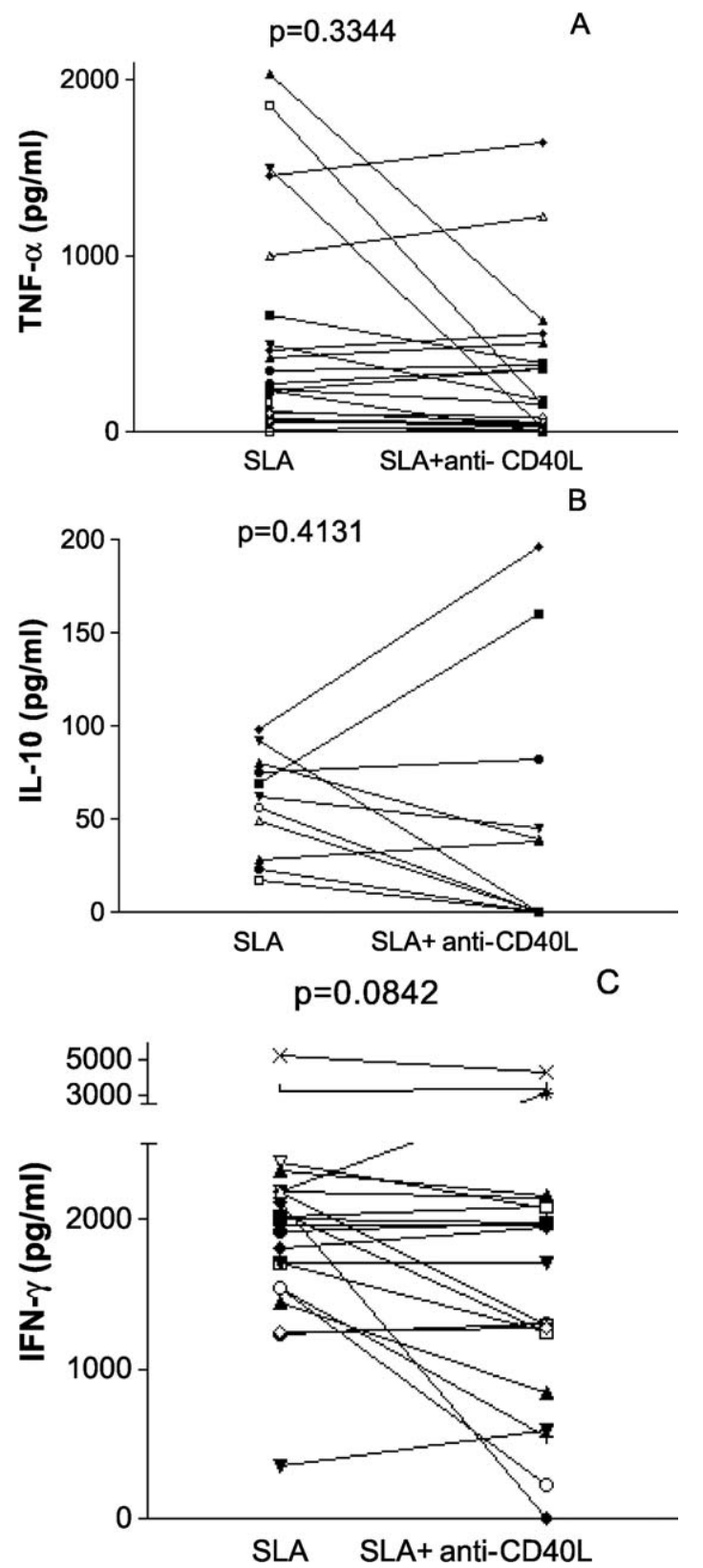

Fig. 6. TNF- $\alpha$ (a), IL-10 (b) and IFN- $\gamma$ (c) production in culture supernatants from PBMC of CL patients stimulated with SLA $(10 \mu \mathrm{g} / \mathrm{ml})$ in the presence or absence of anti-human CD40L $(10 \mu \mathrm{g} / \mathrm{ml})$. Results are expressed in $\mathrm{pg} / \mathrm{ml}$. Each point represents data on one individual. The Wilcoxon matched pairs test was performed and considered significant with $P<0.05$.

mechanism. In the present study, we observed a general downmodulation in cytokine production, suggesting that $\mathrm{T}$ cells from CL patients present a dependence on CD28-B7 costimulation for their cell activation.

Cytokines such as IFN- $\gamma$ and TNF- $\alpha$ are essential to control parasite multiplication, since they act on activation of macrophages, the main parasite-harboring cells [15]. Although they have a protective role, IFN- $\gamma$ and TNF- $\alpha$ are also involved in CL pathogenesis when their production is intense [16]. Our data show a correlation between TNF- $\alpha$ and IFN- $\gamma$ reduction induced by CTLA4-Ig on SLA-stimulated cultures from $\mathrm{PBMC}$ of $\mathrm{CL}$ patients. Interestingly, this observation corre- lated with the data obtained in a recent paper by Antonelli et al. [17]. Analyzing cytokines produced by PBMC from CL patients stimulated with SLA or LACK antigen, as well as the frequency of activated and memory T cells, a positive correlation was found between the frequency of total lymphocytes producing TNF- $\alpha$ or IFN- $\gamma$. Therefore, the same mechanism could be occurring in the present system, where the decrease in one cytokine leads to the decrease of another, as shown by the correlation in their production.

Antonelli et al. [17] also demonstrated a negative correlation between IL-10-producing lymphocytes and TNF- $\alpha$ producing monocytes on PBMC from patients with cutaneous leishmaniais.

In our work, we investigated all possible correlations between the reductions in cytokine production, and only the correlation between IFN- $\gamma$ and TNF- $\alpha$ reduction was significant. However, it is important to observe that IL-10 was detectable in 11 out of 22 patients studied, limiting our analysis. Ajdary et al. [18], studying human CL caused by L. major, also demonstrated undetectable IL-10 levels in culture supernatants. Presently, this does not allow us to assign the decline in TNF- $\alpha$ production to lymphocytes or to monocytes, as observed by Antonelli et al. [17].

We have indeed observed that there is a real difference in the requirement for costimulation, since TT-immunized individuals produce cytokines in the absence of CD28B7 costimulation, whereas PBMC from CL patients do not. It was surprising that $\mathrm{CL}$ patients require CD28-B7 for the activation of $\mathrm{T}$ cells, since these patients have been infected for at least 2 months. In this case, it is supposed that their parasite-specific memory $\mathrm{T}$ cells do not require strong costimulation. Therefore, these results suggest that CD28B7 interaction is necessary to obtain optimal stimulation in CL patients, and $\mathrm{T}$ cells do not gain independence from the requirement of costimulation to produce cytokines upon secondary stimulation

Cytokines such as IL-10 and TGF- $\beta$ counteract IFN- $\gamma$ action [19], leading to an immunmodulatory effect and attenuating pathological effects from intense IFN- $\gamma$ and TNF- $\alpha$ production. Interestingly, blockade of the CD28-B7 pathway led to the downmodulation of both proinflammatory IFN- $\gamma$ and TNF- $\alpha$ and modulatory IL-10. Previous data from the literature [20] show that engagement of CTLA4-B-7 causes an increase in TGF- $\beta$, which could be responsible for the immunosupression observed in murine visceral leishmaniasis. For this reason, we hypothesized that the generalized immunomodulation observed in our results could be due to an increase in TGF- $\beta$ production after CTLA4-B-7 engagement. However, our data show that the general decrease in cytokine production was not due to TGF- $\beta$ production, since the presence of CTLA4-Ig in cultures of CL patients' PBMC stimulated with SLA did not lead to a significant increase in production of this cytokine.

Another possible mechanism to explain the reduction in cytokine production could be alterations in $\mathrm{T}$ cell activation. For this purpose, flow cytometry analyses were performed 
concerning CD25 and CTLA4 surface molecules on both $\mathrm{CD}^{+}$and $\mathrm{CD} 8^{+} \mathrm{T}$ cell populations from cultures stimulated with SLA after CD28-B7 blockade, or not. Although cytokine production was diminished in the presence of CTLA4-Ig, no significant alterations were found in the expression of CD25 and CTLA4 T cell surface markers. Probably the decrease in cytokine production is related to other mechanisms independent of activation marker expression. Several mechanisms have been recently proposed to explain the inhibitory effect of the CTLA4 molecule, such as inhibition of lipid rafts [21], depletion of tryptophan by increasing enzyme indoleamine-2,3-dioxygenase activity [22] and generation of pro-apoptotic kynurenines involved in $\mathrm{T}$ cell regulation [23].

The binding of CD40 on APC causes IL-12 production, leading to IFN- $\gamma$ production [3], cell activation and parasite elimination. In murine leishmaniasis, CD40 activation led to a protective response [14], whereas treatment with antiCD40L diminished IL-12-dependent IFN- $\gamma$ production [24]. In a human primary in vitro sensitization model, CD40CD40L blockade led to a negative modulation of IFN- $\gamma$ production, suggesting a role for this pathway in the early human responses to Leishmania [9]. In the present report, CD40CD40L blockade on PBMC from CL patient cultures stimulated with SLA did not significantly alter TNF- $\alpha$, IL-10 or IFN- $\gamma$ production. Although we observed a strong dependence of PBMC from CL patients on the CD28-B7 pathway to produce cytokines, our results showed that concerning cytokine production, CD40-CD40L interaction was not related to the maintenance of the immune response.

The role of CD40-CD40L interaction in eliciting a protective immune response against Leishmania is controversial. Some authors have shown the importance of this interaction in experimental leishmaniasis [14,24], whereas others have shown that CD40-CD40L interaction is not essential in the immune response against this parasite [25] or other intracellular pathogens [26]. It is possible that CD40-CD40L interactions are really important in the sensitization of human $\mathrm{T}$ cells against Leishmania [9], but not in established ongoing responses observed in patients such as in the present study.

Therefore, the present results showed that CD28-B7 interaction but not CD40-CD40L interaction is important in IFN- $\gamma$, IL-10 and TNF- $\alpha$ production by PBMC from CL patients. Participation of distinct costimulatory pathways in primary and established responses may be of relevance in delineating immunoprophylactic or immunotherapeutic strategies in human leishmaniasis.

\section{Acknowledgments}

We would like to thank Dra Eliane Nascimento and health professionals at Centro de Referências em Doenças Endêmicas Pirajá da Silva (PIEJ). This work was supported by National Institute of Health grant 30609 and CAPES (C. Favali and D. Costa fellowships). A. Barral, M. Barral-Netto and C.I. Brodskyn are senior investigators from CNPq.

\section{References}

[1] T.R. Mosmann, R.L. Coffman, Th1 and Th2 cells: different patterns of lymphokine secretion lead to different functional properties, Annu. Rev. Immunol. 7 (1989) 145-173.

[2] M. Barral-Netto, C.I. Brodskyn, E.M. Carvalho, A Barral, Human_leishmaniasis/cytokines.bahia.br, Braz. J. Med. Biol. Res. 31 (1998) 149-155.

[3] I.S. Grewal, R.A. Flavell, CD40 and CD154 in cell-mediated immunity, Annu. Rev. Immunol. 16 (1998) 111-135.

[4] N.L. Harris, F. Ronchese, The role of B7 costimulation in T-cell immunity, Immunol. Cell Biol. 77 (1999) 304-311.

[5] F.A. Harding, J.G. McArthur, J.A. Gross, D.H. Raulet, J.P. Allison, CD28-mediated signalling co-stimulates murine $\mathrm{T}$ cells and prevents induction of anergy in T-cell clones, Nature 356 (1992) 607-609.

[6] D.B. Corry, S.L. Reiner, P.S. Linsley, R.M. Locksley, Differential effects of blockade of CD28-B7 on the development of Th1 or Th2 effector cells in experimental leishmaniasis, J. Immunol. 153 (1994) 4142-4148.

[7] T.M. Foy, A. Aruffo, J. Bajorath, J.E. Buhlmann, R.J. Noelle, Immune regulation by CD40 and its ligand GP39, Annu. Rev. Immunol. 14 (1996) 591-617.

[8] K.A. Campbell, P.J. Ovendale, M.K. Kennedy, W.C. Fanslow, S.G. Reed, C.R. Maliszewski, CD40 ligand is required for protective cell-mediated immunity to Leishmania major, Immunity 4 (1996) 283-289.

[9] C.I. Brodskyn, G.K. DeKrey, R.G. Titus, Influence of costimulatory molecules on immune response to Leishmania major by human cells in vitro, Infect. Immun. 69 (2001) 665-672.

[10] C.I. de Oliveira, A. Bafica, F. Oliveira, C.B. Favali, T. Correa, L.A. Freitas, E. Nascimento, J.M. Costa, A. Barral, Clinical utility of polymerase chain reaction-based detection of Leishmania in the diagnosis of American cutaneous leishmaniasis, Clin. Infect. Dis. 37 (2003) e149-e153.

[11] O. Bacellar, C. Russo, E.M. Carvalho, Regulation of T cell response to Leishmania antigens by determinants of histocompatibility leukocyte class I and II molecules, Braz. J. Med. Biol. Res. 31 (1998) 15751581.

[12] E.M. Carvalho, W.D. Johnson, E. Barreto, P.D. Marsden, J.L. Costa, S. Reed, et al., Cell mediated immunity in American cutaneous and mucosal leishmaniasis, J. Immunol. 135 (1985) 4144-4148.

[13] P.S. Yamauchi, J.R. Bleharski, K. Uyemura, J. Kim, P.A. Sieling, A. Miller, H. Brightbill, K. Schlienger, T.H. Rea, R.L. Modlin, A role for CD40-CD40 ligand interactions in the generation of type 1 cytokine responses in human leprosy, J. Immunol. 165 (2000) 1506-1512.

[14] W.G. Ferlin, T. Von der Weid, F. Cottrez, D.A. Ferrick, R.L. Coffman, M.C. Howard, The induction of a protective response in Leishmania major-infected BALB/c mice with anti-CD40 mAb, Eur. J. Immunol. 28 (1998) 525-531.

[15] H.W. Murray, B.Y. Rubin, C.D. Rothermel, Killing of intracellular Leishmania donovani by lymphokine-stimulated human mononuclear phagocytes. Evidence that interferon-gamma is the activating lymphokine, J. Clin. Invest. 72 (1983) 1506-1510.

[16] A. Ribeiro-de-Jesus, R.P. Almeida, H. Lessa, O. Bacellar, E.M. Carvalho, Cytokine profile and pathology in human leishmaniasis, Braz. J. Med. Biol. Res. 31 (1998) 143-148.

[17] L.R. Antonelli, W.O. Dutra, R.P. Almeida, O. Bacellar, K.J. Gollob, Antigen specific correlations of cellular immune responses in human leishmaniasis suggests mechanisms for immunoregulation, Clin. Exp. Immunol. 136 (2004) 341-348.

[18] S. Ajdary, M.H. Alimohammadian, M.B. Eslami, K. Kemp, A. Kharazmi, Comparison of the immune profile of nonhealing cutaneous leishmaniasis patients with those with active lesions and those who have recovered from infection, Infect. Immun. 68 (2000) 17601764. 
[19] M. Barral-Netto, A. Barral, C.E. Brownell, Y.A. Skeiky, L.R. Ellingsworth, D.R. Twardzik, et al., Transforming growth factor-beta in leishmanial infection: a parasite escape mechanism, Science 257 (1992) 545-548.

[20] N.A. Gomes, C.R. Gattass, V. Barreto-De-Souza, M.E. Wilson, G.A. DosReis, TGF-beta mediates CTLA-4 suppression of cellular immunity in murine kalaazar, J. Immunol. 164 (2000) 2001-2008.

[21] M. Martin, H. Schneider, A. Azouz, C.E. Rudd, Cytotoxic T lymphocyte antigen 4 and CD28 modulate cell surface raft expression in their regulation of T cell function, J. Exp. Med. 194 (2001) 1675-1681.

[22] D.H. Munn, E. Shafizadeh, J.T. Attwood, I. Bondarev, A. Pashine, A.L. Mellor, Inhibition of T cell proliferation by macrophage tryptophan catabolism, J. Exp. Med. 189 (1999) 1363-1372.
[23] F. Fallarino, U. Grohmann, C. Vacca, R. Bianchi, C. Orabona, A. Spreca, M.C. Fioretti, P. Puccetti, T cell apoptosis by tryptophan catabolism, Cell Death Differ 9 (2002) 1069-1077.

[24] F.P. Heinzel, R.M. Rerko, A.M. Hujer, Underproduction of interleukin-12 in susceptible mice during progressive leishmaniasis is due to decreased CD40 activity, Cell. Immunol. 184 (1998) 129-142.

[25] U.M. Padigel, P.J. Perrin, J.P. Farrell, The development of a Th1-type response and resistance to Leishmania major infection in the absence of CD40-CD40L costimulation, J. Immunol. 167 (2001) 5874-5879.

[26] P. Zhou, R.A. Seder, CD40 ligand is not essential for induction of type 1 cytokine responses or protective immunity after primary or secondary infection with histoplasma capsulatum, J. Exp. Med. 187 (1998) 1315-1324. 